\title{
Model analysis of a declining coastal tourist resort: the case of Avinguda Carles Buigas in Salou, Costa Dorada - opportunities for regeneration
}

\author{
N. Salvadó ${ }^{1}$, I. De Rivera ${ }^{2}$, T. Salvadó ${ }^{1} \&$ D. Lorenzo ${ }^{2}$ \\ ${ }^{1}$ Departamento de Proyectos Arquitectónicos de la UPC, Spain \\ ${ }^{2}$ Unidad Predepartamental de Arquitectura, URV, Spain
}

\begin{abstract}
Salou is a highly specialized tourist resort on the Spanish Mediterranean Coast, located a hundred kilometres south of Barcelona. Within its narrow boundaries of 1.481 ha, Salou hosts 7.4 million overnight stays per year and is home to 52 hotels. Our case study, the area of Avinguda Carles Buigas (CB), which is today the heart of the tourism and leisure industry in the municipality of Salou, was developed during the sixties and seventies as a result of the increasing demand for sun and beach destinations among the European and Spanish middle class. Its hotel density is significant, accounting for 28 out of the total of 52 in the town. Forty years on, the site requires some review due to evidence of urban degradation. Initial analysis has focused on three areas: common space, hotel facilities, and commercial and leisure activities. The results have shown a lack of public and private investment within the area, and a risk of obsolescence of the urban and tourism model. The hotel facilities have not been redeveloped or renovated since their initial development, other than essential maintenance work. Moreover, commercial activities have grown out of control as a result of an increasing demand for specialized leisure and night activities.

Keywords: coastal tourism, urban regeneration, tourism specialization, urban decay, public space quality, hotel improvements, planning, commercial specialization, administrative capacity, urban strategy.
\end{abstract}




\section{Introduction}

The area for study is located in the south-east of the town of Salou, and its backbone is the Avinguda Carles Buigas (CB). This road contains a great deal of commercial activity, and the area acts as the link between the town centre and the Passeig de Jaume I: the town's historic waterfront and major tourism and commercial hub. The work area is $768,082 \mathrm{~m}^{2}$.

It is an urban area, consisting mostly of detached buildings mostly used for hotels and apartment hotels, although there are some small isolated summer houses and apartment blocks used for second homes.

$\mathrm{CB}$ shows evidence of the low quality of the area: the appearance of the businesses is poor, the quality of the public space is lower and the urban fabric is in the process of decaying. In addition, the area is hampered by seasonal demands, which leads to it being stressed for six months during the high season and empty for the rest of the year.

Within this scenario, there is an urgent need for intervention to change the current decay/lack of investment/decay cycle. This is an opportunity to take action with stakeholders in the area: local government, hotel managers, businesses, the public, tour operators, etc. As well as the initial analysis, this study aims to provide and implement solutions by modifying the area: by means of temporary and permanent initiatives with the common goal of regenerating the zone and improving its urban and tourism quality of life.

\section{Context and analysis}

Salou is located $100 \mathrm{~km}$ south of Barcelona in the geographical area of Camp de Tarragona, which is considered the second major economic area in Catalonia. The Camp is a complex area, in which towns, tourism and industry have coexisted in a very intense and possibly contradictory manner since the last century.

The tourist developments along the Mediterranean coast are of a seasonal nature. Salou is one of these areas, with urban growth linked to tourism and heavy variations in the population between seasons. In the summer months the population increases sixfold, which defines the rhythm of economic activity. The town of Salou is small in area $-14.8 \mathrm{~km}^{2}$ - and its population density, according to the census, is similar to that of other neighbouring towns, at 1,807 inhab. $/ \mathrm{km}^{2}$. However, when the figures for visitors during the peak summer season are taken into account, the density increases to 11,296 inhabitants $/ \mathrm{km}^{2}$, similar to Seoul, Delhi, Calcutta, Casablanca or Lima (Demographia [1]).

Salou is a benchmark for tourism on the Catalan coast, and was in tenth place in Spain in terms of number of overnight stays recorded in 2013 (Observatorio del FEDECT [2]). The municipality has a total of 69 tourist establishments and 3 campsites providing a total of 30,000 to 37,000 hotel places (beds) (Ajuntament de Salou [3], IDESCAT [4]). Its economic activity is concentrated in the months of July and August, although there is a growing trend towards an extension of the season. However, currently, the hotel sector closes completely between the 
second fortnight in November and the beginning of the second half of February, coinciding with the temporary closure of the Port Aventura theme park.

Urban development has polarized during the growth of the town. The hotel structures are concentrated at one end of the town around the Avenue CB and the theme park, whereas the urban facilities have been placed at the other end of the town in the area known as Carrer Barcelona.

The local authorities' perception that the area of Avinguda CB was undergoing a process of urban decay prompted them to carry out a study on the ground, as the first step in a wider plan which aims to develop specific proposals for improvement.

Over four months, from January to April 2014, graphic and statistical documents were produced in order to identify the logic and organization behind the study area. The analysis considers three points: the physical constraints of the site, the urban constraints and the economic and use constraints. The drawing of the existing was the main analysis method because it necessarily has to be the starting point in our efforts to learn about the site (Venturi et al. [5]). Understanding how the city works in real life is essential to creating a consistent strategy for improving social and economic life (Jacobs [6]).

\section{The study area}

\subsection{Physical constraints}

Within the defined study area, there are two different areas that take CB as the dividing axis: the northern part, which has larger plots and is topographically flatter; and the southern part, bordering the sea, where the topography creates a relief of cliffs and coves.

In the more abrupt southern area, the plots have to make their relationship with the street level topographically compatible. Smaller plots, containing isolated buildings used for housing, adapt to the existing topography. Meanwhile, the large hotel plots create large flat areas for swimming pools and leisure areas, which produce walls that act as barriers between the public and private spaces.

On most built-up plots, the search for the best (south-facing) orientation determines the position of the buildings and the swimming pools located inside blocks, with priority given to the comfort area (Figure 1). The buildings along the $\mathrm{CB}$ are an exception to this organizational structure, which prioritizes the position of the swimming pool over the main façade of the building. As a result, the hotels and apartments are aligned to the street, prioritizing their commercial position.

\subsection{Urban planning constraints}

The planning regulations governing this area are the Salou Municipal Urban Development Plan (MUDP) (2003). This plan provides for a population increase of 9,000 people in 7 years - a figure which has now been exceeded - and the 

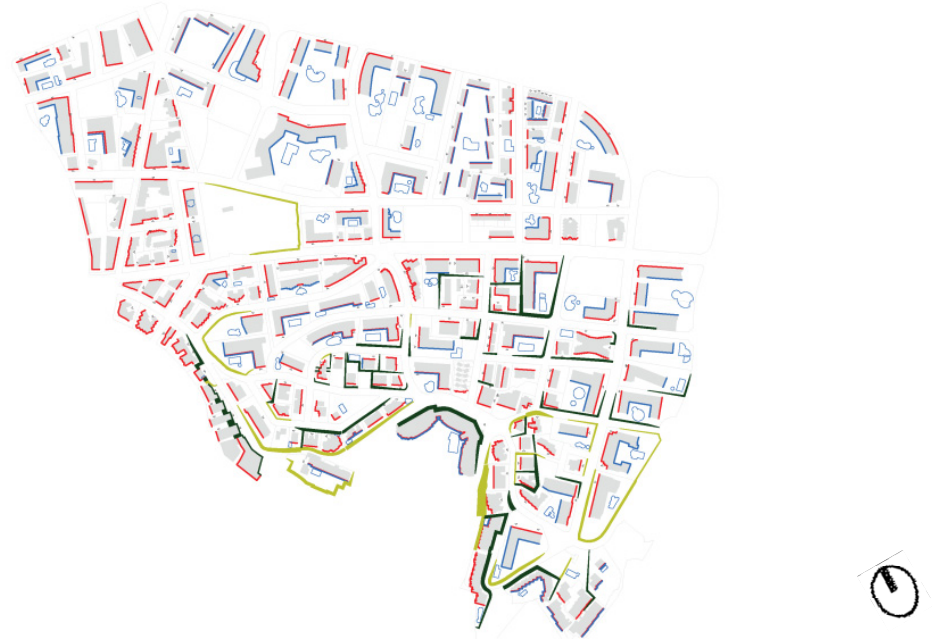

Figure 1: "Comfort” map and main façades.

creation of 13,450 new hotel rooms (mainly around Port Aventura), and anticipates 2.5 million visitors each year.

An analysis of the urban planning regulations covering hotels showed that:

1. None of the hotels comply with the MUDP in force in 2003.

2. Only one hotel (Hotel Sol Piràmide) complies with the building floor area because a specific code in the regulations (13b6) enables it to occupy $40 \%$ of the plot.

3. The other hotels have a maximum building floor area in the MUDP of $20 \%$, although on the ground building floor area levels vary between $30 \%$ and $40 \%$ of the land on the plot.

4. Only seven hotels meet the provisions of the regulations concerning height, which suggests that they all amply exceed the maximum building floor area permitted.

Consequently, in accordance with current regulations, any hotel that is demolished and rebuilt will see a reduction in its built area and, therefore, its number of rooms. The loss of building floor area can be considered a key factor in the decline in investments in the hotel sector within the $\mathrm{CB}$ area. Furthermore, the expectations created by a possible future amendment of the plan may be delaying applications for licenses to renew hotels.

Regarding the ground floor, municipal planning regulations allow it to be used for commercial purposes in most of the properties within the study area. Likewise, regulations state that the building types must be isolated, leading to contradictions in the administration of the $8 \mathrm{~m}$ strip between the building and the street. Thus, this band that should preserve privacy between housing on the ground floor and the street, or between the hotel area and the street, is occupied 
on the ground floor when the activity that takes place is commercial, regardless of the ban on the occupation (Figure 2). Pressure from traders wishing for access to the main flow of consumers is considerable.

This occupation, which originally started with a canopy or awning to protect products from the sun, has resulted in increasingly impenetrable enclosures, in part due to inaction on the part of the authorities. Thus, despite the regulatory provisions in place (Municipal Ordinance on Canopies and Signs, March 2007), all this has done is provide some degree of order for the increase in the canopies that occupy almost all the entire frontage of the buildings on the main streets in the $\mathrm{CB}$ area.

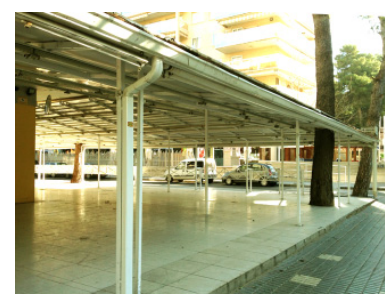

Figure 2: Various types of canopies in the area.

\subsection{Economic and use constraints}

The topography of the area means that there are two different road structures in the northern and southern areas. To the south-west, roads parallel to the contours create slopes that are gentler and accessible for pedestrians. However, those running perpendicular to the coastline have gradients of almost $10 \%$.

Public land use is limited to streets, pavements, pedestrian areas, parks and gardens with a total surface of $22.3 \mathrm{Ha}$. The $9.2 \mathrm{Ha}$ allocated to roads and the 2.6 Ha allocated to public parking (11.68\%) are representative of the high amount of public land set aside for cars (Figure 3). Private land is mostly used for hotel activities. The area has a very high number of hotels, with 22 hotels and 6 apartment hotels being built between 1963 and 2000. However the number of beds available in the area varies due to the seasonality of the sector, from 2,064 beds in the second half of February to 12,375 beds between June and September.

The state of the hotel sector has been analyzed using two complementary data sets: (a) the volume of construction work carried out during the period from 2000 to 2014, and (b) the degree of customer satisfaction based on data from three Internet operators: Booking, Atrapalo and Tripadvisor.

Regarding the volume of work undertaken during the period 2000-2014, 123 licenses were granted for a total amount of 3,510,046 €, with two particularly significant years: 2002 and 2011. These figures represent an average investment in improvements of 4,821.50 € per hotel per year. In most cases, this work was maintenance reforms involving specific items: repairs in outdoor leisure areas and minor indoor repairs. Only two cases (Hotel Santa Mònica Playa and Hotel Marinada) completely refurbished some of their floors. This analysis suggests 


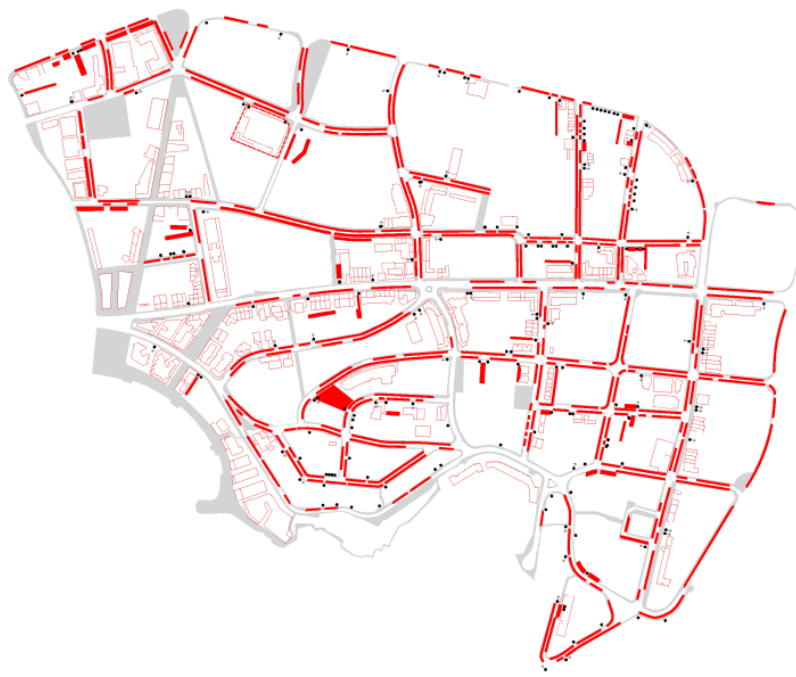

Figure 3: Map of the shopping area, parking areas and vehicle access points inside plots.

that investment in the hotel industry is frozen. With regard to customer satisfaction, a lower level of satisfaction emerges in the area to the south of CB.

There is a high degree of specialization among commercial outlets. Bars and pubs account for $68.4 \%$ of the total commercial surface area. Significantly, 300 linear metres (LM) of façade are dedicated to this use in Carrer Brussel-les and 140 LM in Carrer Murillo, two of the main streets in the area. Meanwhile, souvenir shops represent $8.3 \%$ of the total and are mostly located on the Avinguda CB, where they occupy 240 LM.

If shops are analyzed in terms of the type or degree of enclosure (open canopy, covered canopy or closed canopy) and their activity (trade, tourism or leisure), the open canopy and covered canopy categories can be related to leisure activities (bars, restaurants, ice cream parlours, pubs, discos and amusement arcades), whereas most of the premises in the closed canopy category are shops. Likewise, there is a considerable contrast in the intensity of commercial activity between summer and winter, reflecting the high level of seasonality in tourism (Figure 5). On a commercial area of $21,730 \mathrm{~m}^{2}$, the area covered by trade falls from $19,367 \mathrm{~m}^{2}$ (summer day), or $89.1 \%$ of the total, to $1,124 \mathrm{~m}^{2}$ (winter day), $5.1 \%$ of the total. The same is true of commercial activity at night, which covers an area of $12,421 \mathrm{~m}^{2}$ (summer night), or $57.1 \%$ of the total, falling to $4,194 \mathrm{~m}^{2}$ (winter night), or $19.3 \%$ of the total.

The real estate market provides evidence that there are considerable differences between $\mathrm{CB}$ and other areas, which highlight the process of decay. Firstly, a review of the rental market shows that prices are up to $23 \%$ lower in the area studied than in other areas of the municipality. At the same time, monthly rents during the season are 2 or 3 times higher than an annual rental fee, 


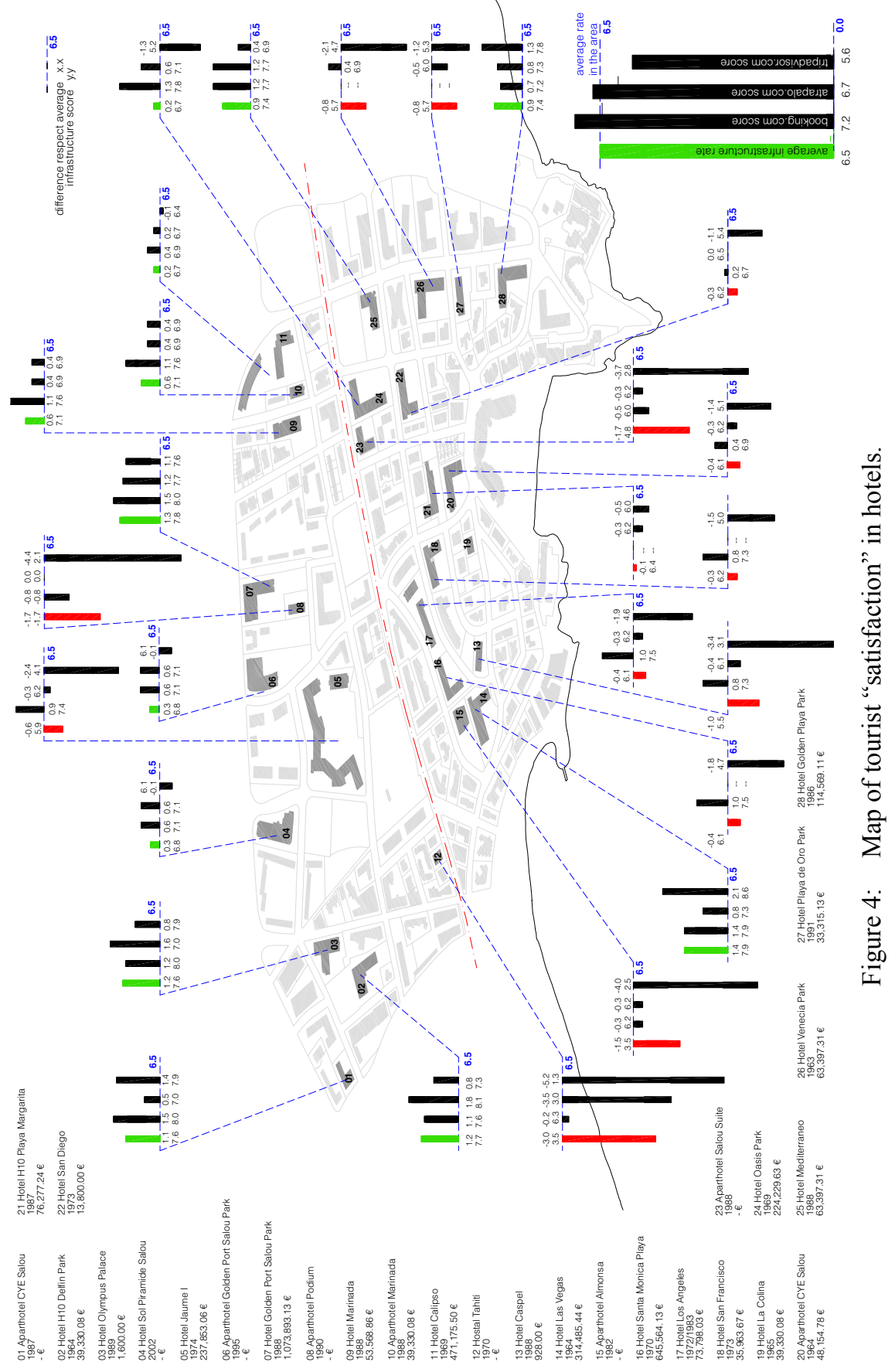


which is sufficient incentive for owners to keep their properties empty for most of the year. Moreover, the analysis carried out indicates a lower level of demand for apartments as permanent and stable residences than elsewhere in the town. Likely reasons for this are the poorer quality of the properties, a lower level of preservation, a high level of disadvantaged population with limited purchasing power, poor spatial quality and excessive pressure from tourism.

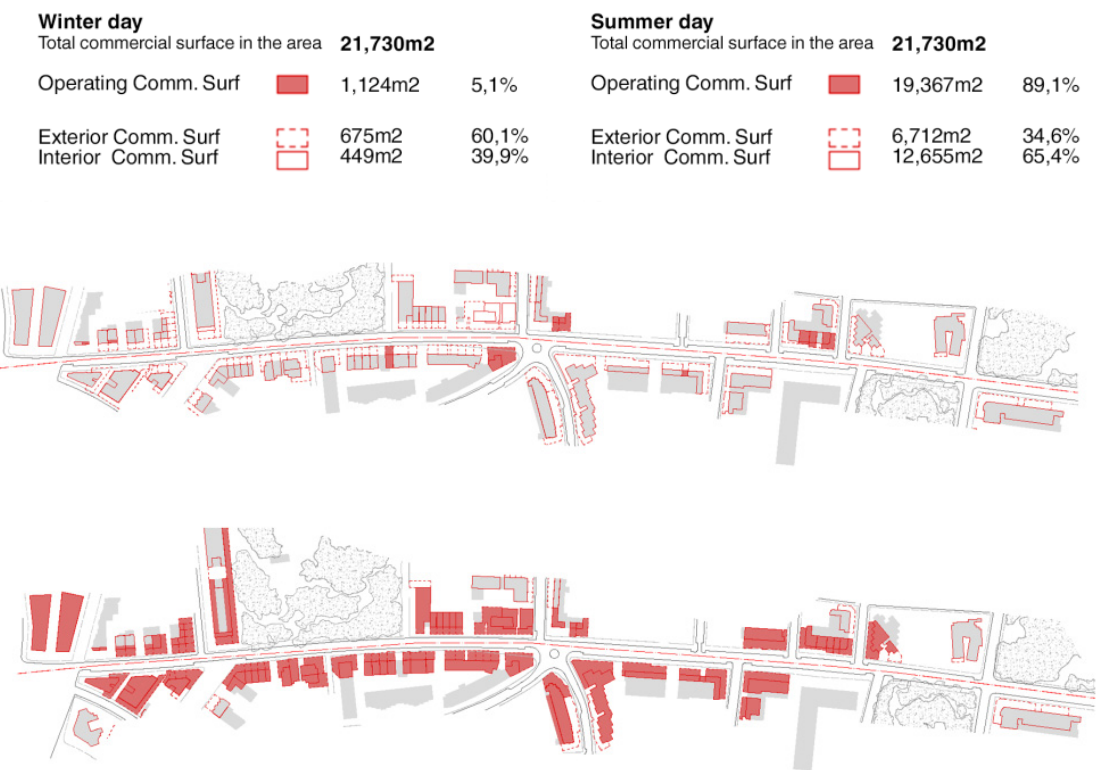

Figure 5: Map of shops open on Av. Carles Buigas on a winter day and on a summer day.

\subsection{The public space}

The area in the public domain accounts for $30 \%$ of the study area, of which only $38.41 \%$ is guaranteed space for pedestrians 24 hours a day (pavements and pedestrian streets), $20.35 \%$ is occupied by parks and gardens with restricted opening hours, and the remaining $41.24 \%$ is allocated to vehicles.

In an area that receives 170,000 visitors at times of maximum stress, only one shopping street (Saragossa), and the Camí de Ronda, a seafront promenade, are spaces for the exclusive use of pedestrians. The rest, with a pavement width of less than $2 \mathrm{~m}$ in most cases, penalizes pedestrian mobility and prioritizes private vehicles (Figure 6).

In addition, the sharp topography of the southern area has led to the creation of levelling platforms on the larger plots, leading to insurmountable and impermeable boundaries, and an impoverishment of the quality of the street and public space.

Furthermore, an analysis of the tree types in the area in terms height and leaf type (deciduous and evergreen) indicated the quality of shade provided. This 
enabled us to ascertain the level of comfort on the streets in the summer, and to identify which streets are most comfortable for pedestrians.
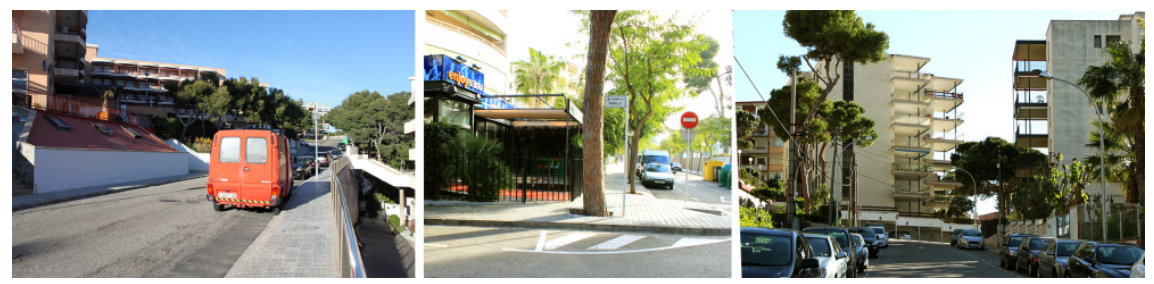

Figure 6: Photographs of conflicts in public space: impact of vehicles, width of pavements, non-existent trees or trees in the middle of the pavement, boundaries and impermeability of free private spaces.

\section{Final thoughts}

\subsection{On the hotel and residential fabric}

A total of $85 \%$ of hotel establishments in the area are more than 25 years old and $92 \%$ are 3 -star hotels. The analysis of the area shows that in most cases the renovation or refurbishment of a hotel WOULD NOT lead to an increase in overnight stays or a better rating by its visitors.

Other policies promoting comprehensive rehabilitation are proposed in order to tackle the conflict generated by the MUDP and the reduction in the floor area ratio. The focus is on promoting more sustainable practices than the current option of demolition and new construction (Druot et al. [7]). These practices also make it easier for infrastructures to function without the whole building having to be closed down. It would also help to enhance the architecture of the $1950 \mathrm{~s}$ and 1960s, which, to date, has been neglected by its owners and ignored by residents and visitors.

Nevertheless, any stimulus aimed at hotel regeneration needs to be controlled and accompanied by a contribution to and improvement of the urban space.

Some strategies have been proposed:

1. Encouraging rehabilitation, energy self-sufficiency, environmental sustainability and the recovery of free space with native trees and vegetation in exchange for increases in the covered area built.

2. Allowing the existing covered area to be maintained in cases of demolition and new construction, only in cases in which community facilities are improved by way of compensation: increasing the size of the public space and its quality.

3. Establishing systems for the transfer or sale of development rights (TDR) in an attempt to capture land value added and reallocate funds to the urban improvement of the area. 


\subsection{On shops and the Avinguda Carles Buigas}

The density of commercial activities along the Avinguda CB suggests the need to consider strategies designed to restrict the passage of vehicles on the street and the pacification of most of the roads in the neighbourhood. There is an obvious need to redesign the road layout in the area, its limits and its uses.

The lack of shops providing essential products makes the establishment of a stable population difficult. Strategies are required to extend the hotel season and encourage the development of mixed urban fabrics, incorporating new uses and activities. It is also essential to organize and regulate the nightlife in the area, in order to avoid undesirable interference with other activities.

The strip between the building and the street creates the character of the neighbourhood. The uncontrolled use of this area by traders comes at the expense of the ultimate quality of the public space. Despite the regulations governing canopies, which are supposedly retractable and removable, a threshold between the private and the public sphere is created. The results go against public and private interests.

In order to improve the quality of the public space and trade it is proposed:

1. To ensure continuity or discontinuity in terms of pavements and height between the street and the lateral strip.

2. To promote a consistent, uniform and understandable solution for canopies which administers the space as a continuation of the street or shop.

3. To recover pavement width in exchange for the regularization and consolidation of commercial space that invades the street.

4. To acknowledge the asymmetry of the Avinguda $\mathrm{CB}$, extending it at both ends and creating a pole of attraction at the empty side of the street, thus lengthening the daily routes taken by pedestrians.

\subsection{On the public space}

A ring road around the area means that traffic will stay out of the centre and hierarchizes the roads, making the streets more pedestrian friendly and standardizing the road surfaces and the pavements.

A detailed study of entrances to the hotels and the creation of service roads should resolve the topographical discontinuities between the street and the inside of plots, fostering good relations between the two and enhancing the permeability between the public and private space.

Green spaces should also be guaranteed and encouraged not only in hotel and residential areas but also in the public space. The tree cover also needs to be redesigned and increased, and special attention should be paid to pedestrianfriendly and redeveloped streets because, in most cases, it is non-existent (Figure 7). A good selection of tree varieties for the streets will ensure shaded areas, providing increased coolness and comfort for pedestrians. 


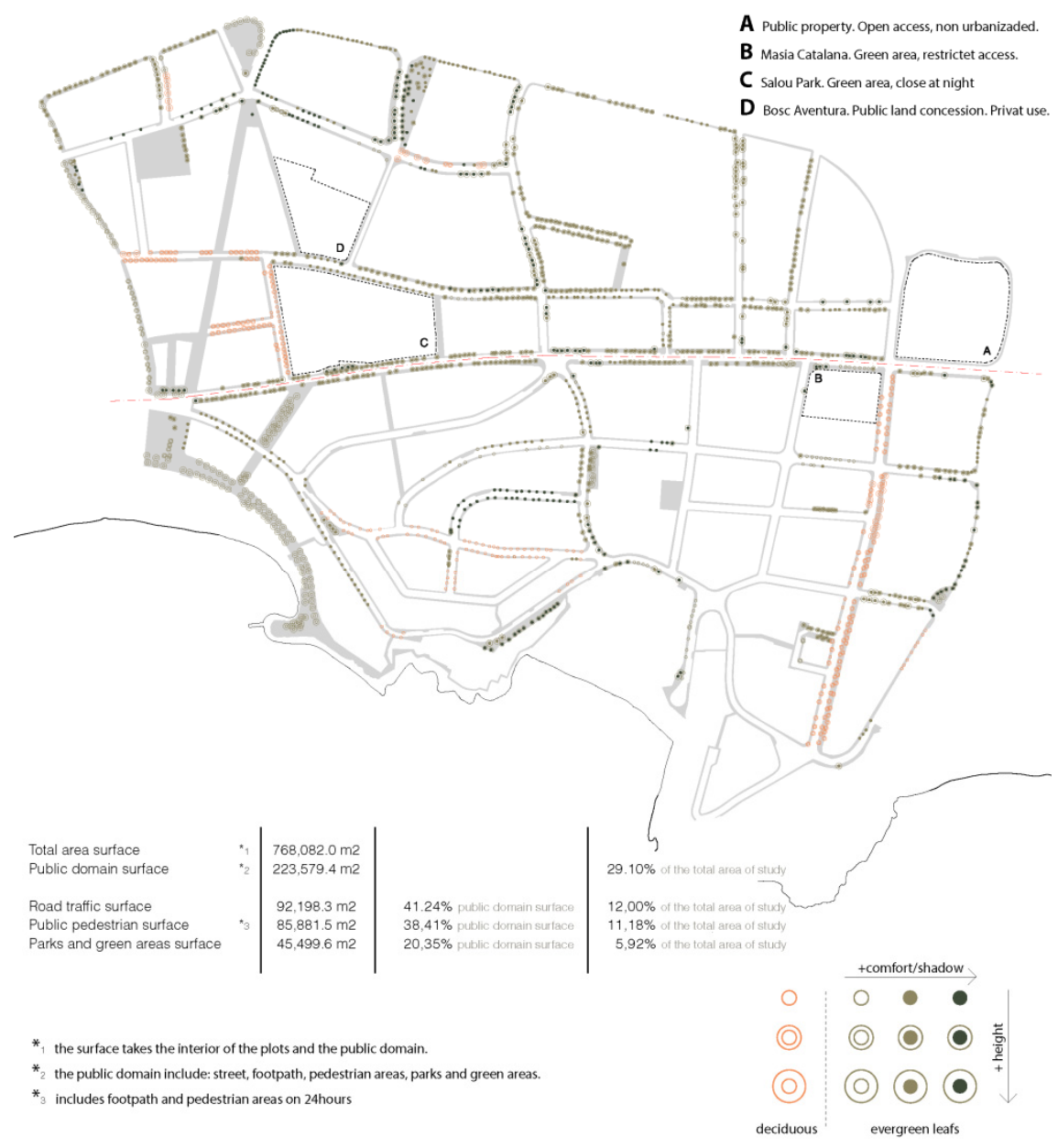

Figure 7: Map of shadow quality and pedestrian exclusive areas.

Parking in the street must also be reduced. Hotel car parks are available and underused, and so are an opportunity for freeing the streets from the omnipresence of the car.

\subsection{A final note - political will}

Political will is essential for defining urban strategies and the model to be implemented. There are two potential scenarios: (a) the area is recognized as a tourist and leisure complex and specialises in these activities, or (b) the area is regarded as one part of a complex town, and the coexistence of the tourist and the stable population can be fostered by embedding the CB area within Salou's urban structure. 


\section{References}

[1] Demographia, Demographia World Urban Areas, (Built Up Urban Areas or World Agglomerations), 11th annual edition, http://www.demographia.com, January 2015.

[2] Observatorio del FEDECT, Fundación de Estudios Turísticos de la Costa Dorada, http://www.pct-turisme.cat/, 2014.

[3] Ajuntament de Salou, Àrea de Promoció Econòmica. Dades socioeconòmiques del municipi de Salou, 2012.

[4] IDESCAT, Institut d'Estadística de Catalunya. http://www.idescat.cat, 2014.

[5] Venturi, R.; Izenour, S.; Scott Brown, D., Learning from Las Vegas Revised Edition: The Forgotten Symbolism of Architectural Form Paperback, 1977.

[6] Jacobs, J., The Death and Life of Great American Cities, Random House, New York, 1961.

[7] Druot, F.; Lacaton, A.; Landrove, S.; Vassal, J.-P., Plus: Large-scale housing developments. An exceptional case. Barcelona, Ed. Gustavo Gili, 2007. 